\title{
Effect of Nano-Magnesium Hydride on the Thermal Decomposition Behaviors of RDX
}

\author{
Miao Yao, ${ }^{1}$ Liping Chen, ${ }^{1}$ Guoning Rao, ${ }^{1}$ Jianxin Zou, ${ }^{2}$ Xiaoqin Zeng, ${ }^{2}$ and Jinhua Peng ${ }^{1}$ \\ ${ }^{1}$ School of Chemical Engineering, Nanjing University of Science \& Technology, Nanjing, Jiangsu 210094, China \\ ${ }^{2}$ Shanghai Engineering Research Center of Magnesium Materials and Application, School of Materials Science and Engineering, \\ Shanghai Jiao Tong University, Shanghai 200240, China
}

Correspondence should be addressed to Liping Chen; clp2005@hotmail.com

Received 10 December 2012; Revised 4 February 2013; Accepted 18 February 2013

Academic Editor: Kemin Zhang

Copyright (c) 2013 Miao Yao et al. This is an open access article distributed under the Creative Commons Attribution License, which permits unrestricted use, distribution, and reproduction in any medium, provided the original work is properly cited.

\begin{abstract}
In order to improve the detonation performance of hexahydro-1,3,5-trinitro-1,3,5-triazine (RDX) explosive, addictives with high heat values were used, and magnesium hydride $\left(\mathrm{MgH}_{2}\right)$ is one of the candidates. However, it is important to see whether $\mathrm{MgH}_{2}$ is a safe addictive. In this paper, the thermal and kinetic properties of $\mathrm{RDX}$ and mixture of $\mathrm{RDX} / \mathrm{MgH}_{2}$ were investigated by differential scanning calorimeter (DSC) and accelerating rate calorimeter (ARC), respectively. The apparent activation energy $(E)$ and frequency factor $(A)$ of thermal explosion were calculated based on the data of DSC experiments using the Kissinger and Ozawa approaches. The results show that the addition of $\mathrm{MgH}_{2}$ decreases both $E$ and $A$ of $\mathrm{RDX}$, which means that the mixture of $\mathrm{RDX} / \mathrm{MgH}_{2}$ has a lower thermal stability than RDX, and the calculation results obtained from the ARC experiments data support this too. Besides, the most probable mechanism functions about the decomposition of RDX and RDX/MgH were given in this paper which confirmed the change of the decomposition mechanism.
\end{abstract}

\section{Introduction}

Metal hydrides belong to the hydrogen storage material, which have been widely applied for energy storage carriers in recent years. However, metal hydrides are also attracting significant attention as one of the potential fuel components of energetic materials due to their peculiar properties. Metal hydrides have high activity and they can provide high heat values in the process of explosion.

In middle of 1960s, the former Soviet Union conducted the research on the application of metal hydrides for energetic materials. It was found that the metal hydrides gave off a large amount of heat when they were burning and caused relatively lower flame temperature due to the generation of light molecular weight gases. As a result, adding metal hydrides to propellants is likely to lead higher energetic density. For example, propellants containing aluminum hydride $\left(\mathrm{AlH}_{3}\right)$ have 9.8 to $39.2 \mathrm{~N} \cdot \mathrm{s} / \mathrm{kg}$ higher specific impulses than propellants containing Be. Recently, Russia has applied it to solid propellants and fuel air explosive weapons [1].
Nitrocellulose propellant composition containing $\mathrm{AlH}_{3}$ was proposed in 1970s in USA [2]. It was also reported that adding magnesium hydride $\left(\mathrm{MgH}_{2}\right)$ in some explosives such as TNT, tetryl, and C-4 will increase the total work capacity generated by organic, noninitiating explosives [3]. Selezenev et al. [4] considered the influence of aluminum, magnesium and their hydride powders on the detonation characteristics of the compositions based on ammonium nitrate, hexahydro1,3,5-trinitro-1,3,5-triazine (RDX), and cyclotetramethylenetetranitramine (HMX). It concluded that the detonation velocity in the compositions with hydride powders were higher than in the composition with metal powders. Besides, $\mathrm{MgH}_{2}$ was also applied as a pyrotechnic composition which provides improved ignition rates and increased burning time without reduction in luminous intensity [5].

From the above-mentioned researches, it can be found that metal hydrides have great potential as additive components for energetic materials. Among all the metal hydrides, $\mathrm{MgH}_{2}$ has a high hydrogen storage capacity up to $7.6 \mathrm{wt} \%$. 
TABLE 1: Data of DSC analyses on RDX and RDX/MgH $\mathrm{Mg}_{2}$ mixture.

\begin{tabular}{|c|c|c|c|c|c|c|}
\hline \multirow{2}{*}{ Sample } & \multirow{2}{*}{$\beta$} & \multirow{2}{*}{$\mathrm{m} / \mathrm{mg}$} & \multirow{2}{*}{$\begin{array}{c}\text { Melting process } \\
T_{\text {onset }}{ }^{\circ} \mathrm{C}\end{array}$} & \multicolumn{3}{|c|}{ Decomposition process } \\
\hline & & & & $T_{p 1} /{ }^{\circ} \mathrm{C}$ & $T_{p 2} /{ }^{\circ} \mathrm{C}$ & $\Delta H_{d} / \mathrm{J} \cdot \mathrm{g}^{-1}$ \\
\hline \multirow{4}{*}{ RDX } & 1 & 1.07 & 203.00 & - & 225.86 & 2179.06 \\
\hline & 2 & 1.13 & 201.88 & - & 232.22 & 2619.00 \\
\hline & 4 & 1.15 & 201.79 & 232.41 & 239.76 & 1763.61 \\
\hline & 8 & 0.94 & 198.95 & - & 242.72 & 2558.51 \\
\hline \multirow{4}{*}{$\mathrm{RDX}+10 \mathrm{wt} \% \mathrm{MgH}_{2}$} & 1 & 1.14 & 200.94 & - & 223.22 & 4027.00 \\
\hline & 2 & 1.07 & 202.29 & - & 231.92 & 2512.24 \\
\hline & 4 & 1.03 & 203.05 & 234.26 & 240.65 & 2048.55 \\
\hline & 8 & 1.20 & 198.60 & - & 244.41 & 2045.80 \\
\hline
\end{tabular}

Where $\beta$ means the heating rate, the subscripts 1 and 2 are for the first peak and the second peaks respectively, $T_{\text {onset }}$ is the initial decomposing temperature, and $T_{p}$ is the peak temperature. $\Delta H_{d}$ is the heat release in decomposition process.

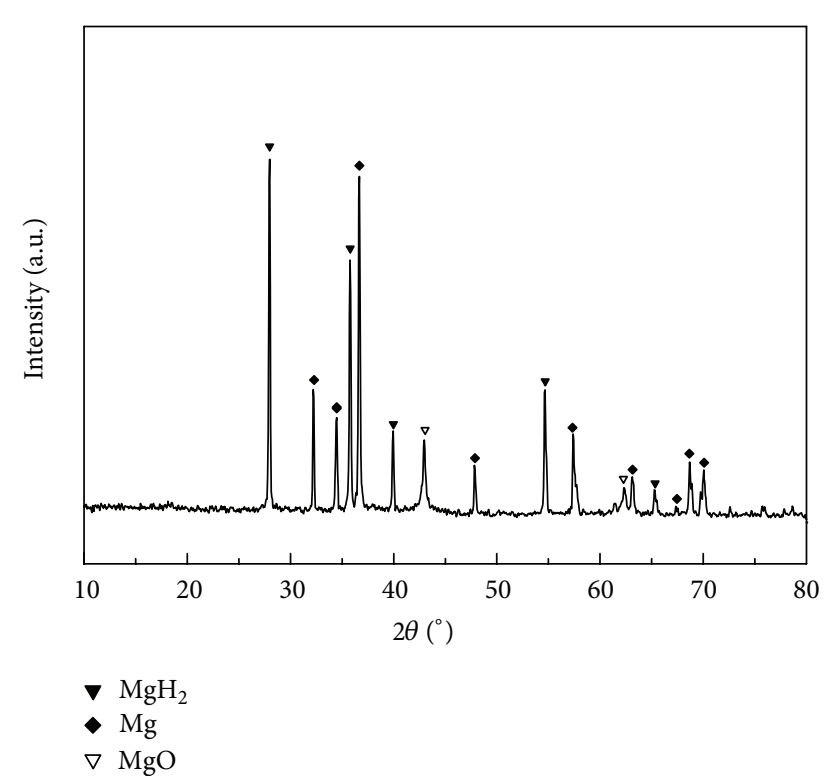

Figure 1: XRD pattern of $\mathrm{MgH}_{2}$ powder.

However, as an additive, $\mathrm{MgH}_{2}$ should be of a good compatibility with the original explosives or propellants and possess a satisfactory thermal stability. In this paper, thermal behaviors of RDX and the mixture of $\mathrm{RDX} / \mathrm{MgH}_{2}$ were investigated by differential scanning calorimeter (DSC) and accelerating rate calorimeter (ARC). In addition, the hazard characterizations of the mixtures were analyzed in order to ensure the safe application of $\mathrm{MgH}_{2}$ in $\mathrm{RDX}$.

\section{Experimental}

2.1. Materials. Nano- $\mathrm{MgH}_{2}$ used in this paper was obtained from Shanghai Engineering Research Center of Magnesium Materials and Applications [6]. It was prepared through a DC Arc Plasma method followed by hydrogenation under high hydrogen pressure at $400^{\circ} \mathrm{C}$. The details about the preparation and microstructures of the $\mathrm{MgH}_{2}$ can be found in the references [7]. RDX was dried at $60^{\circ} \mathrm{C}$ to constant weight.

2.2. Powder X-ray Diffraction. X-ray diffraction (XRD) was utilized to analyze the phase components of the hydrides. The XRD apparatus used was made by Bruker (type: D8 ADVANCE, $\mathrm{Cu} \mathrm{K} \alpha$ radiation source).

2.3. DSC Analysis. DSC is a routine tool to study the thermal stability, heat generation caused by phase transition and chemical reaction, kinetic parameters, decomposition of reactive substances, and so forth. In this paper, the DSC apparatus used was made by Mettler Toledo (type: DSC1). $\mathrm{MgH}_{2}$ powder was tested at $10^{\circ} \mathrm{C} / \mathrm{min}$ and the mixtures of $\mathrm{RDX} / \mathrm{MgH}_{2}$ were heated at a constant rate $\left(1,2,4,8^{\circ} \mathrm{C} / \mathrm{min}\right)$ in nitrogen atmosphere from 25 to $500^{\circ} \mathrm{C}$. The stain steel crucible was used.

2.4. ARC Analysis. ARC is an effective tool for hazards evaluation of reactive substance. Compared with DSC, ARC possesses the characteristic of larger sample quality and adiabatic experimental environment. A lightweight spherical titanium bomb was used in the experiment. The instrument used was made by Thermal Hazard Technology (type: esARC). The ARC experiments were started at ambient pressure of air. The standard ARC procedure of heat-wait-search was used [8].

\section{Results and Discussion}

3.1. XRD Result. The XRD pattern of $\mathrm{MgH}_{2}$ is shown in Figure 1. Besides $\mathrm{MgH}_{2}$, the existence of $\mathrm{Mg}$ and $\mathrm{MgO}$ was also detected in the powder.

3.2. Thermal Behaviors of $\mathrm{MgH}_{2}$ Powder. The DSC curve of $\mathrm{MgH}_{2}$ powder is shown in Figure 2. An endothermic peak of $\mathrm{MgH}_{2}$ appears at $481^{\circ} \mathrm{C}$, which is different from the values reported in the literature $[9,10]$. It is because metal hydrides release hydrogen at different temperatures due to the various surface conditions from different preparation methods. For instance, Huot et al. [9] found that $\mathrm{MgH}_{2}$ made 


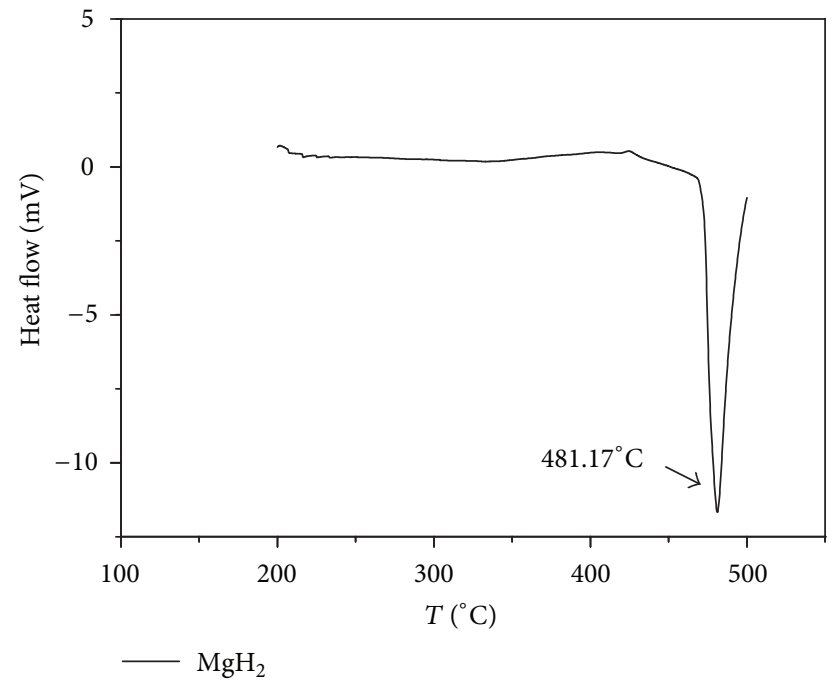

Figure 2: DSC curve of $\mathrm{MgH}_{2}$ powder.

by ball milling began to decompose at $396^{\circ} \mathrm{C}$, while $\mathrm{MgH}_{2}$ synthesized through a direct-hydriding method decomposed at about $287^{\circ} \mathrm{C}[10]$.

3.3. DSC Analyses on $\mathrm{RDX}$ and $\mathrm{RDX} / \mathrm{MgH}_{2}$ Mixture. The DSC curves of RDX and RDX containing $10 \mathrm{wt} \% \mathrm{MgH}_{2}$ at different heating rates of $1,2,4$, and $8^{\circ} \mathrm{C} / \mathrm{min}$ are shown in Figures 3(a)-3(d). The decomposition temperatures of these samples are shown in Table 1 also with the quantities of the heat release. It can be seen from the curves that adding nano$\mathrm{MgH}_{2}$ powder has no significant effect on the melt point of RDX. As for the decomposition process of RDX, it has at least two stages which can be observed obviously from Figures 3(a)-3(c). This result confirms to the literature research [11]. However, there is only one exothermic peak in the DSC curve of RDX at $8^{\circ} \mathrm{C} / \mathrm{min}$.

Brill and Brush [12] investigated the mechanism of thermal decomposition of RDX, HMX, and some other cyclic nitramine explosives based on the T-jump/FTIR and SMATCH/FTIR spectroscopy. The mechanism of thermal decomposition was presented that the $\mathrm{C}-\mathrm{N}$ and $\mathrm{N}-\mathrm{N}$ bonds break at the same time, as shown in formula of (1) and (2). It is considered that the low temperature and slow heating rate are benefit to the breakdown of $\mathrm{C}-\mathrm{N}$ bonds and make the RDX go through a long decomposition in molten state which is favorable for the generation of $\mathrm{CH}_{2} \mathrm{O}$. Formula (1) is an exothermic reaction $(-212.3 \mathrm{~kJ} / \mathrm{mol})$. In addition, high temperature and rapid heating are helpful to the breakdown of $\mathrm{N}-\mathrm{N}$ bonds, and it is an endothermic reaction $(+117.2 \mathrm{~kJ} / \mathrm{mol})$. At last, the following reaction shown in formula (3) releases a lot of heat:

$$
\begin{gathered}
\left(\mathrm{CH}_{2} \mathrm{NNO}_{2}\right)_{3} \longrightarrow 3\left(\mathrm{CH}_{2} \mathrm{O}+\mathrm{N}_{2} \mathrm{O}\right) \\
\left(\mathrm{CH}_{2} \mathrm{NNO}_{2}\right)_{3} \longrightarrow 3(\mathrm{HCN}+\mathrm{HONO}) \text { or } \\
3\left(\mathrm{HCN}+\mathrm{H}^{-}+\mathrm{NO}_{2}\right) \\
5 \mathrm{CH}_{2} \mathrm{O}+7 \mathrm{NO}_{2} \longrightarrow 7 \mathrm{NO}+3 \mathrm{CO}+\mathrm{CO}_{2}+5 \mathrm{H}_{2} \mathrm{O} .
\end{gathered}
$$

Based on the above theory, different peak shapes of RDX in Figures 3(a)-3(c) can be explained. When the heating rate is slow, the breakdown of $\mathrm{C}-\mathrm{N}$ bonds is the dominant reaction and this causes a gentle and slow heat release in the early stage of decomposition. Then, the reaction shown in formula (3) occurs and forms a short spike in DSC curve. On the contrary, when the heating rate increases to $8^{\circ} \mathrm{C} / \mathrm{min}$, the reaction shown in formula (2) becomes dominant and absorbs part of heat which may be due to the slight concave between $210^{\circ} \mathrm{C}$ to $230^{\circ} \mathrm{C}$ in curve (d) of RDX. Therefore, the two stages of RDX's decomposition are not observed in Figure 3(d).

As shown in the graphs, adding $10 \mathrm{wt} \%$ of $\mathrm{MgH}_{2}$ has some effect on the peak shape of RDX's decomposition. Adding $\mathrm{MgH}_{2}$ makes the shoulder peak become sharper especially at the heating rate of $1^{\circ} \mathrm{C} / \mathrm{min}$. However, the hydrogen releasing temperatures of $\mathrm{MgH}_{2}$ used in this paper are far below the decomposition temperature of RDX. So, it can be considered that the effect on the peak shape is mainly due to the metal hydride itself but not the resolved products.

$\mathrm{MgH}_{2}$ used in this paper was prepared through hydrogenation of $\mathrm{Mg}$ ultrafine powders and the high transformation-induced lattice distortion will cause intense cracks in the powder particles. As a result, lots of hydrogen atoms exist in the gaps on the surface of crystal cells [10]. Palopoli and Brill [13] proposed a opinion about the breakdown of $\mathrm{N}-\mathrm{N}$ bonds of cyclic nitramine that the $\mathrm{H}$ atoms in the $-\mathrm{CH}_{2}$ - group transfer to nearby $-\mathrm{NO}_{2}$ group firstly, which results in $\mathrm{N}-\mathrm{N}$ bonds' breakdown. Therefore, lots of $\mathrm{H}$ atoms in the gaps of $\mathrm{MgH}_{2}$ may increase the opportunity for the interaction between $\mathrm{H}$ atoms and $-\mathrm{NO}_{2}$ group and promote the generation of $\mathrm{NO}_{2}$. As a strong oxidizer, $\mathrm{NO}_{2}$ can react with $\mathrm{MgH}_{2}$ and provide extra heat which makes the second exothermic peak of RDX become obvious [14].

3.4. Kinetic Parameters Getting from DSC. Potential hazards always associate with the thermal behavior of energetic materials, so it is essential to evaluate the stability and carry out the decomposition kinetic. In this paper, kinetic parameters were determined using the Kissinger approach [15] and the Ozawa approach [16] in the meantime as shown in formulas (4) and (5), respectively, the results are shown in Table 2,

$$
\begin{gathered}
\ln \left(\frac{\beta}{T_{p}^{2}}\right)=\ln \left(\frac{R A}{E}\right)-\frac{E}{R} \frac{1}{T_{p}}, \\
\lg \beta=\lg \frac{A E}{R F(\alpha)}-2.315-0.4567 \frac{E}{R T_{p}} .
\end{gathered}
$$

As shown in Table 2, the values of $E$ calculated by the Kissinger method are in good agreement with the values calculated by the Ozawa method. Adding $10 \mathrm{wt} \% \mathrm{MgH}_{2}$ decreases the activation energy of RDX from $260.57 \mathrm{~kJ} / \mathrm{mol}$ to $202.74 \mathrm{~kJ} / \mathrm{mol}$. The frequency factors are also following this order. Therefore, the thermal stability lowered to a certain extent after adding $\mathrm{MgH}_{2}$ to $\mathrm{RDX}$. 


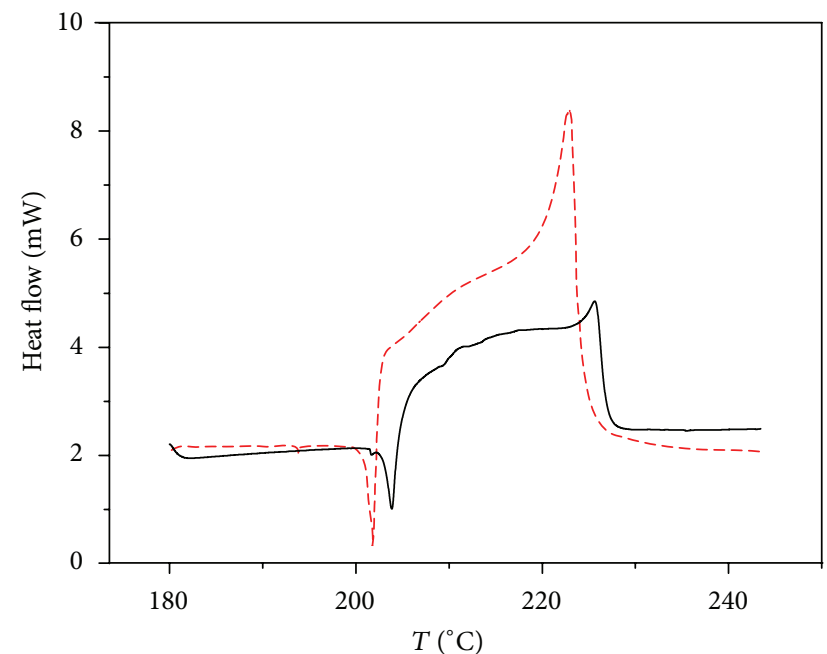

(a) DSC curve at heating rate of $1^{\circ} \mathrm{C} / \mathrm{min}$

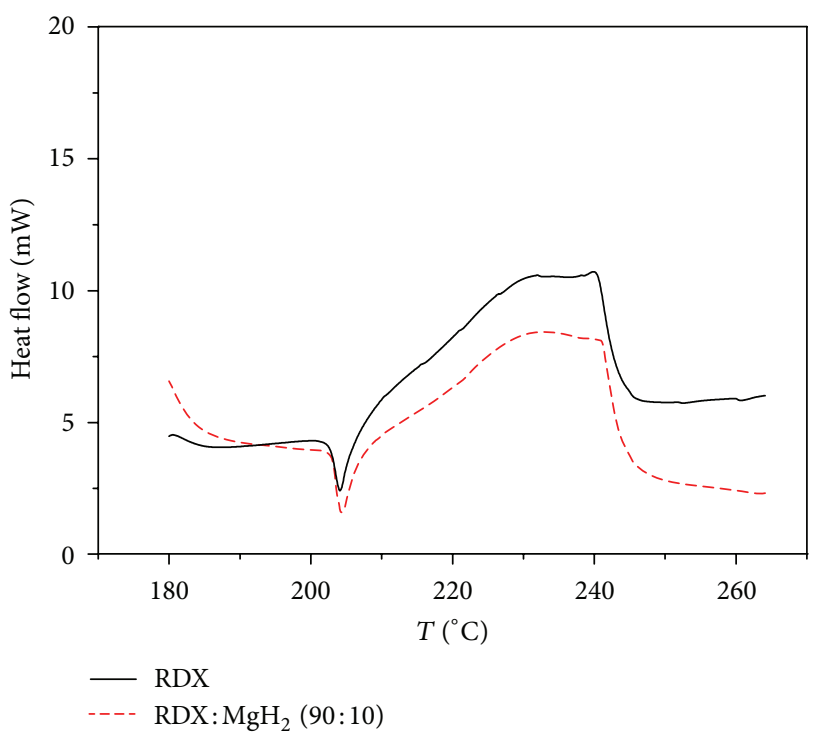

(c) DSC curve at heating rate of $4^{\circ} \mathrm{C} / \mathrm{min}$

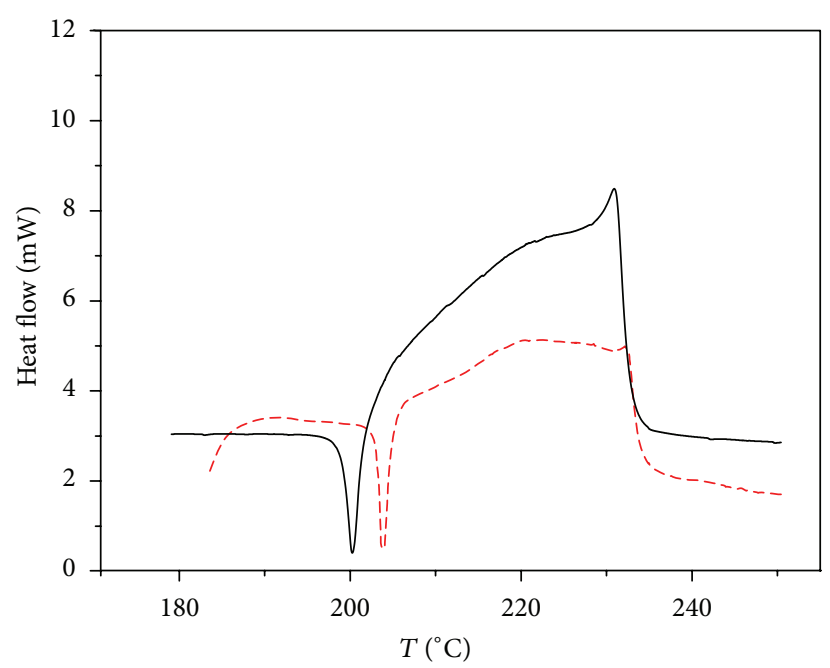

(b) DSC curve at heating rate of $2^{\circ} \mathrm{C} / \mathrm{min}$

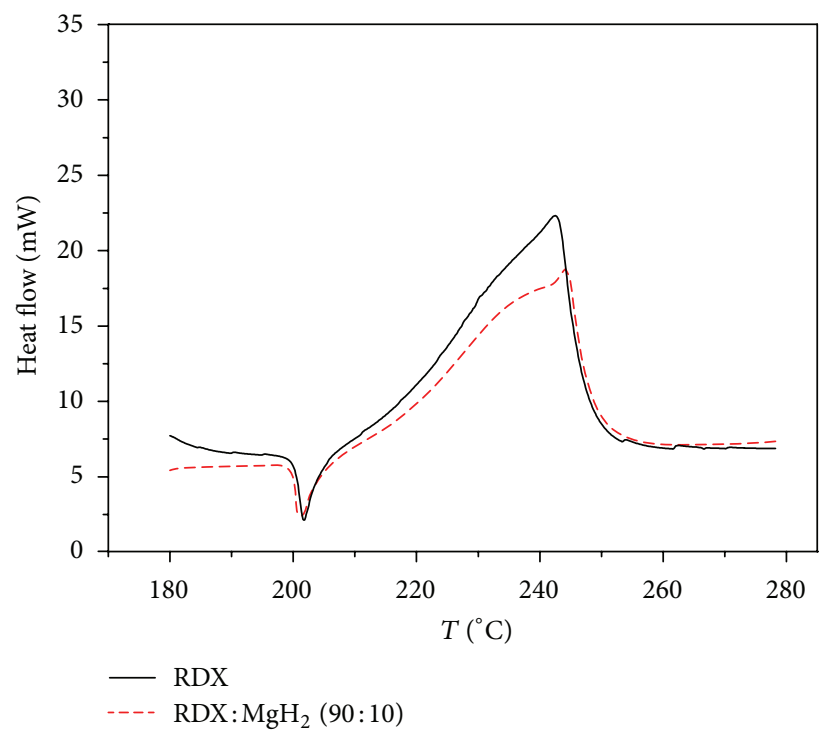

(d) DSC curve at heating rate of $8^{\circ} \mathrm{C} / \mathrm{min}$

FIGURE 3: DSC curves of RDX and $\mathrm{RDX} / \mathrm{MgH}_{2}$ mixture at different heating rate.

TABLE 2: Kinetic parameters obtained by Kissinger and Ozawa approaches.

\begin{tabular}{|c|c|c|c|c|c|}
\hline \multirow{2}{*}{ Sample } & \multicolumn{3}{|c|}{ Kissinger } & \multicolumn{2}{|c|}{ Ozawa } \\
\hline & $E(\mathrm{~kJ} / \mathrm{mol})$ & $\ln A\left(\mathrm{~s}^{-1}\right)$ & $r^{2}$ & $E(\mathrm{~kJ} / \mathrm{mol})$ & $r^{2}$ \\
\hline RDX & 260.57 & 55.93 & 0.98006 & 255.81 & 0.98127 \\
\hline $\mathrm{RDX}+10 \mathrm{wt} \% \mathrm{MgH}_{2}$ & 202.74 & 42.06 & 0.99331 & 200.80 & 0.99389 \\
\hline
\end{tabular}

Where $E$ is the activation energy, $A$ is the frequency factor, and $r^{2}$ is the linear correlation coefficient.

3.5. ARC Results. The experimental conditions and results are listed in Table 3. The curves of temperature-time, pressure-time, self-heating-rate-temperature, and so forth are drawn in Figures 4 and 5.

The sample quantities for ARC test were smaller than usual, which was constrained by the fierce reaction of the explosive samples. As a result, the thermal inertia was big, and it may lead to higher ignited temperature and smaller pressure. The heat release should be correct because of the heat evolution that was used to heat the titanium ball. Whereas, the data from the ARC test still had some reference significance to analyze the thermal stability of these mixtures.

Since the amount of sample is fairly small, the influence caused by a different sample weight was great. In this case, it may be improper to draw a conclusion from the data in Table 3 directly. However, it is feasible to compare the thermal 


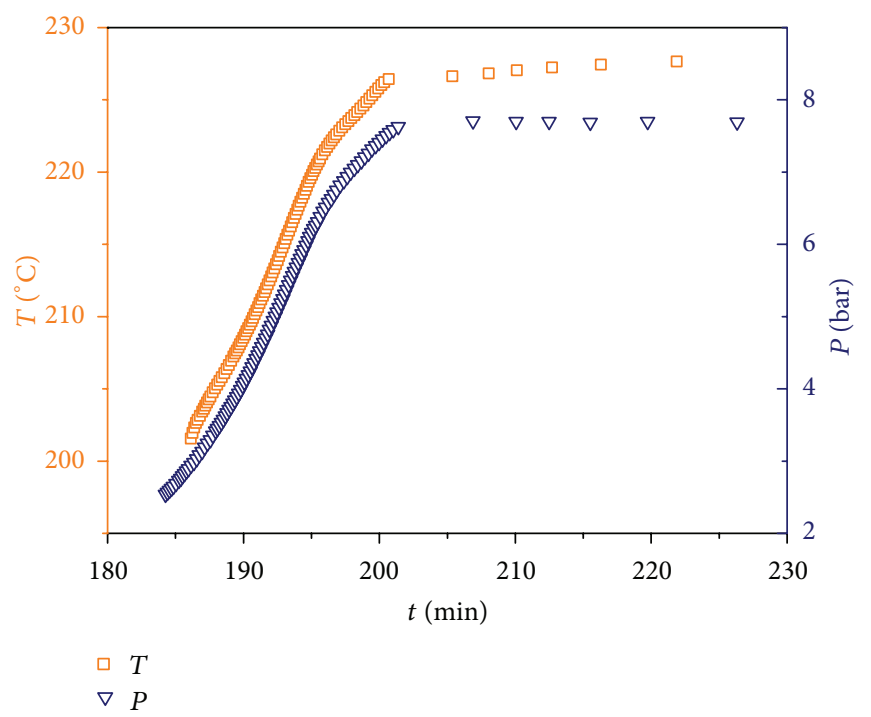

(a) Temperature/pressure versus time

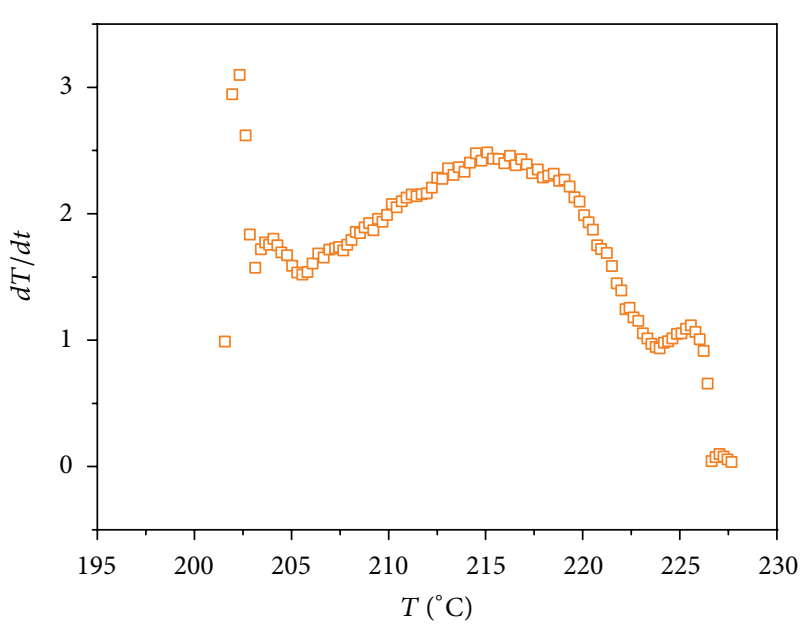

(b) Self-heating rate versus temperature

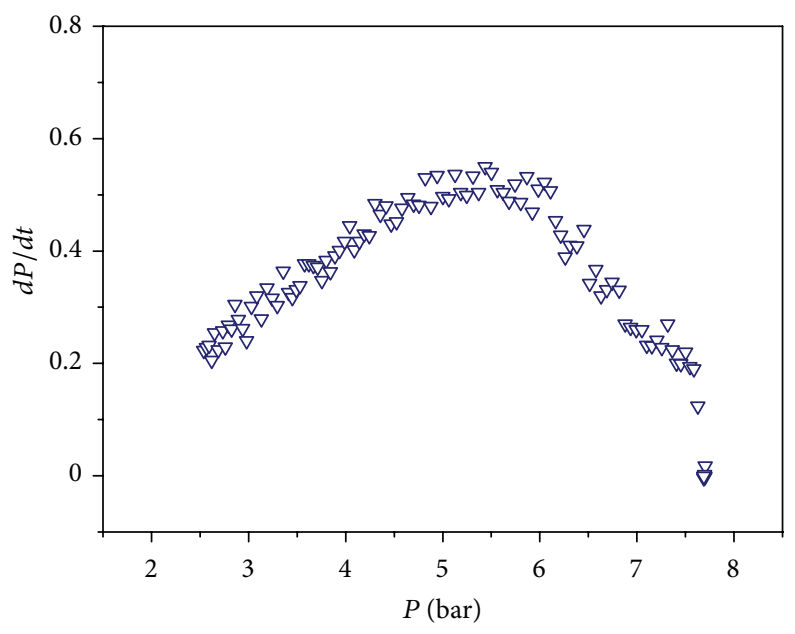

(c) Pressure rising rate versus temperature

FIgURE 4: Adiabatic decomposition curves of RDX.

TABLE 3: Data of ARC analyses on RDX and $\mathrm{RDX} / \mathrm{MgH}_{2}$ mixture.

\begin{tabular}{lcc}
\hline Sample & $\mathrm{RDX}$ & $\mathrm{RDX}+5 \mathrm{wt} \% \mathrm{MgH}_{2}$ \\
\hline$M(\mathrm{~g})$ & 0.071 & 0.063 \\
$T_{0}\left({ }^{\circ} \mathrm{C}\right)$ & 201.569 & 199.220 \\
$T_{f}\left({ }^{\circ} \mathrm{C}\right)$ & 227.653 & 221.791 \\
$\Delta T\left({ }^{\circ} \mathrm{C}\right)$ & 26.084 & 22.571 \\
$m_{0}\left({ }^{\circ} \mathrm{C} \cdot \mathrm{min}^{-1}\right)$ & 0.020 & 0.020 \\
$m_{m}\left({ }^{\circ} \mathrm{C} \cdot \mathrm{min}^{-1}\right)$ & 2.485 & 1.901 \\
$T_{m}\left({ }^{\circ} \mathrm{C}\right)$ & 215.082 & 219.657 \\
$P_{m}($ bar $)$ & 7.698 & 6.714 \\
$\Delta P($ bar $)$ & 5.160 & 4.012 \\
\hline
\end{tabular}

Where $M$ is mass of sample; $T_{0}$ is the initial temperature; $T_{f}$ is the final temperature; $\Delta T$ is the adiabatic temperature rise; $m_{0}$ and $m_{m}$ are self-heat at $T_{0}$ and self-heat at $T_{f} ; T_{m}$ is temperature at maximum rate; $P_{m}$ is the maximum pressure; $\Delta P$ is the adiabatic pressure rise.

stability of these two samples by the kinetic parameters getting from the data.
Figures 4(b) and 5(b) show the different variation of selfheating rate between RDX and $\mathrm{RDX} / \mathrm{MgH}_{2}$ mixture. Similar change of the variation of pressure rising rate can be observed in Figures 4(c) and 5(c). From the figures, the self-heating rate of RDX achieves its maximum at the middle of the decomposition process and drops at the high-temperature period. However, the self-heating rate of $\mathrm{RDX} / \mathrm{MgH}_{2}$ mixture achieve maximum at the high-temperature period as well as the pressure rising rate. That is to say, adding $\mathrm{MgH}_{2}$ influences the decomposition process of RDX in the high temperature stage, and it is consistent with the conclusion of DSC experiments.

In this paper, the apparent activation energy of adiabatic decomposition process was calculated by a method using pressure data [17], and the following formula (6) was used:

$$
\ln \frac{m_{p}}{f\left(\left(p-p_{0}\right) / \Delta p\right)}=\ln (A \cdot \Delta p)-\frac{E}{R} \cdot \frac{1}{T}
$$


TABLE 4: 29 kinetic models.

\begin{tabular}{lccccccc}
\hline No. & $f(\alpha)$ & No. & $f(\alpha)$ & No. & $f(\alpha)$ & No. & $f(\alpha)$ \\
\hline 1,2 & $(1-\alpha)^{m}, m=1,2$ & 9 & $1 / 3(1-\alpha)^{-2}$ & 16 & {$[-\ln (1-\alpha)]^{-1}$} & 23 & $(1 / 4)(1-\alpha)[-\ln (1-\alpha)]^{-3}$ \\
3 & 1 & 10 & $(1 / 4)(1-\alpha)^{-3}$ & 17 & $3 / 2(1-\alpha)[-\ln (1-\alpha)]^{1 / 3}$ & 24 & $(3 / 2)\left[(1-\alpha)^{-1 / 3}-1\right]^{-1}$ \\
4 & $2(1-\alpha)^{1 / 2}$ & 11 & $(2 / 3) \alpha^{1 / 2}$ & 18 & $2(1-\alpha)[-\ln (1-\alpha)]^{1 / 2}$ & 25 & $3 / 2(1-\alpha)^{2 / 3}\left[1-(1-\alpha)^{1 / 3}\right]^{-1}$ \\
5 & $2(1-\alpha)^{3 / 2}$ & 12 & $(1 / 2) \alpha^{-1}$ & 19 & $3(1-\alpha)[-\ln (1-\alpha)]^{2 / 3}$ & 26 & $6(1-\alpha)^{2 / 3}\left[1-(1-\alpha)^{1 / 3}\right]^{1 / 2}$ \\
6 & $3(1-\alpha)^{2 / 3}$ & 13 & $2 \alpha^{1 / 2}$ & 20 & $4(1-\alpha)[-\ln (1-\alpha)]^{3 / 4}$ & 27 & $4(1-\alpha)^{1 / 2}\left[1-(1-\alpha)^{1 / 2}\right]^{1 / 2}$ \\
7 & $4(1-\alpha)^{3 / 4}$ & 14 & $3 \alpha^{1 / 2}$ & 21 & $(1 / 2)(1-\alpha)[-\ln (1-\alpha)]^{-1}$ & 28 & $(3 / 2)(1+\alpha)^{2 / 3}\left[(1+\alpha)^{1 / 3}-1\right]^{-1}$ \\
8 & $\frac{1}{2}(1-\alpha)^{-1}$ & 15 & $4 \alpha^{1 / 2}$ & 22 & $(1 / 3)(1-\alpha)[-\ln (1-\alpha)]^{-2}$ & 29 & $(3 / 2)(1-\alpha)^{4 / 3}\left[(1-\alpha)^{-1 / 3}-1\right]^{-1}$ \\
\hline
\end{tabular}

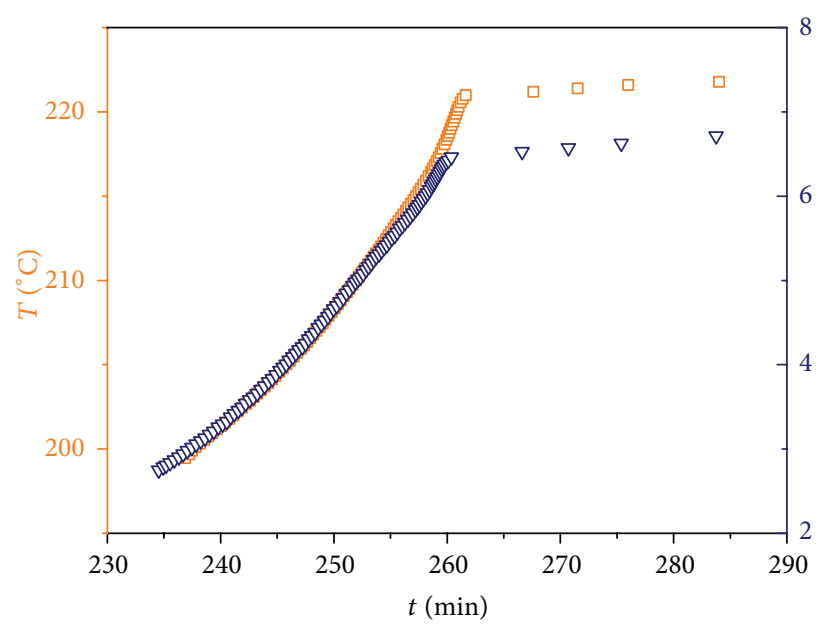

$\square T$

$\nabla P$

(a) Temperature/pressure versus time

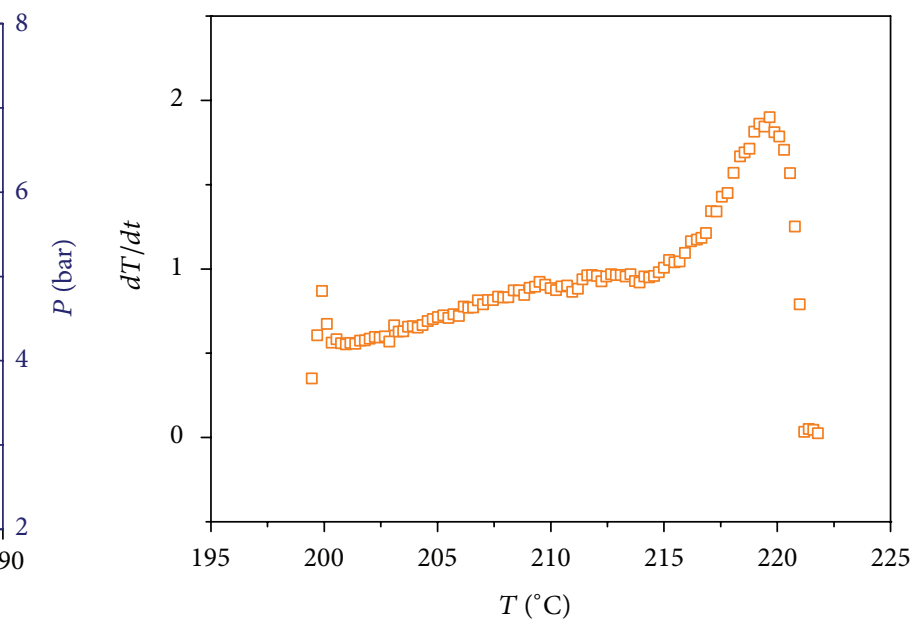

(b) Self-heating rate versus temperature

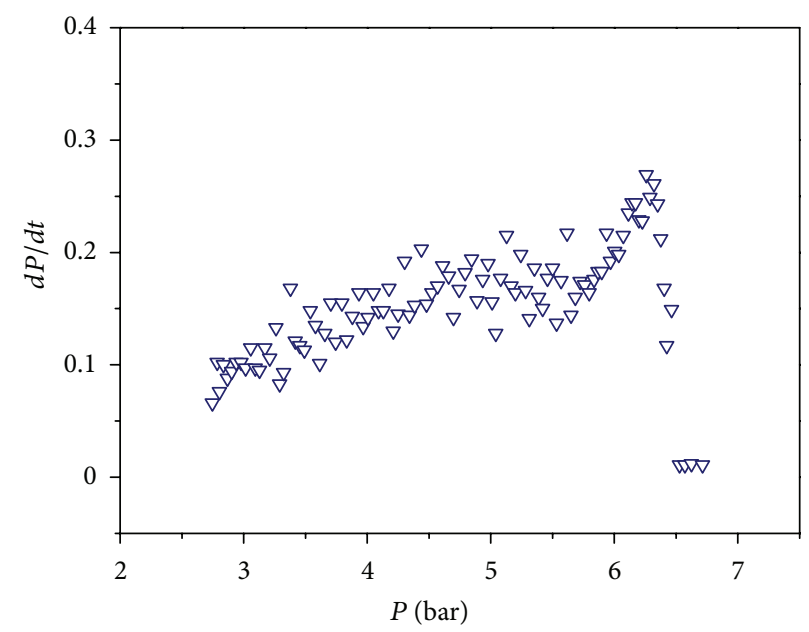

(c) Pressure rising rate versus temperature

FIgURe 5: Adiabatic decomposition curves of RDX $+5 \mathrm{wt} \% \mathrm{MgH}_{2}$.

where $p$ is the pressure at $t ; m_{p}=d p / d t ; \Delta p=p_{f}-p_{0}$ is the pressure rise; $f()$ symbolizes the kinetic model in form of differential equation. The plot of $\ln \left(m_{p} / f\left(\left(p-p_{0}\right) / \Delta p\right)\right)$ versus $T^{-1}$ should give a straight line with a slope $-E / R$ providing the kinetic model which is correctly chosen.
Different kinetic models are used to try to find the best linear fitting, from which the activation energy can be calculated. The 29 kinetic models are listed in Table 4.

By applying the 29 kinetic models in formula (6) and plot $\ln \left(m_{p} / f\left(\left(p-p_{0}\right) / \Delta p\right)\right)$ versus $T^{-1}$, the best linear fitting 


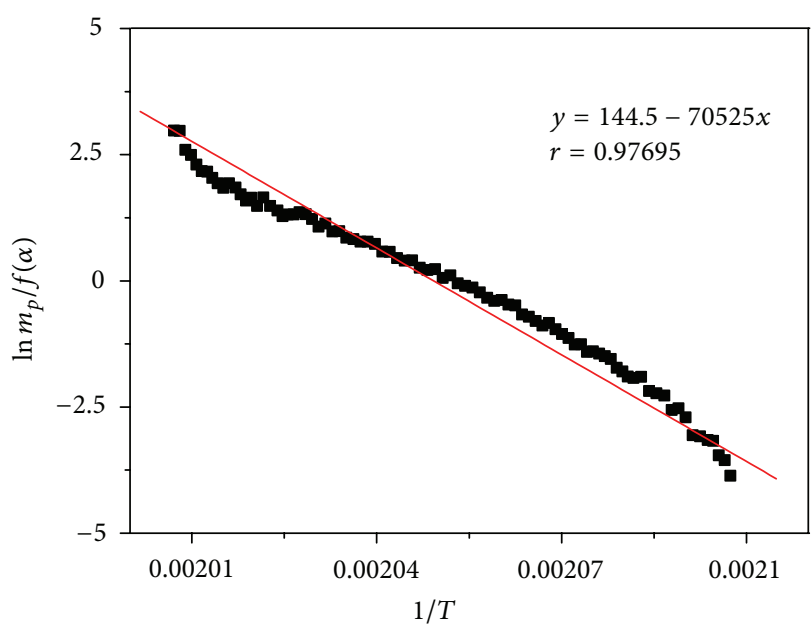

(a) $\mathrm{RDX}$

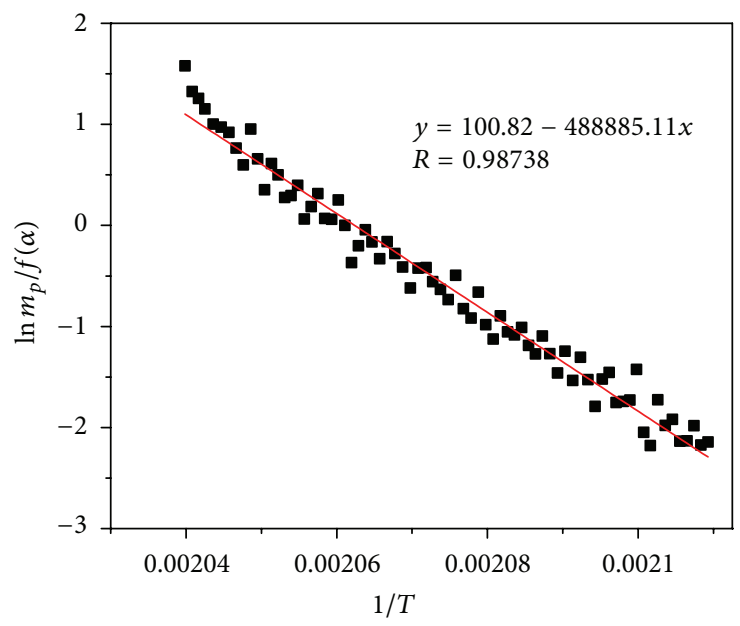

(b) $\mathrm{RDX}+5 \mathrm{wt} \% \mathrm{MgH}_{2}$

FIGURE 6: Simulating lines which have highest correlation with original data.

TABLE 5: Regression results of kinetic parameters.

\begin{tabular}{lcccc}
\hline Sample & $E(\mathrm{~kJ} / \mathrm{mol})$ & $\ln A\left(\mathrm{~s}^{-1}\right)$ & $f(\alpha)$ & $r$ \\
\hline RDX & 586.34 & 142.86 & 21 & 0.97695 \\
RDX + 5 wt $\% \mathrm{MgH}_{2}$ & 406.43 & 99.18 & 2 & 0.98738 \\
\hline
\end{tabular}

result can be screened. The highest correlation coefficient and the corresponding kinetic model are shown in Table 5 as well as the activation energy and frequency factor. Figure 6 shows the simulating lines which have the highest correlation with original data.

Samples used here were not exactly the same as the samples used for DSC experiment, the metal hydride content was $5 \mathrm{wt} \%$. Meanwhile, the values of $E$ and $A$ in Table 5 are quite different from the value mentioned above. It is also due to the high thermal inertia. However, the kinetic parameters calculated from the ARC's data show the same rules as the kinetic parameters calculated from the DSC's data. Adding $5 \mathrm{wt} \% \mathrm{MgH}_{2}$ decreased the values of $E$ and $A$ obviously. Besides, the most probable mechanism function has also changed.

\section{Conclusions}

(1) The addition of $10 \mathrm{wt} \% \mathrm{MgH}_{2}$ to $\mathrm{RDX}$ has no obvious or regular effect on the melt point and the initial decomposition temperature of RDX. The second exothermic peak grows dramatically after the addition of $\mathrm{MgH}_{2}$ to $\mathrm{RDX}$, and the exothermic heat quantity increases at the low heating rate.

(2) Kinetic parameters obtained from the DSC data show that the mixture of $\mathrm{RDX} / \mathrm{MgH}_{2}$ has the lower values of $E$ and $A$, which means that the stability of mixture $\mathrm{RDX} / \mathrm{MgH}_{2}$ is worse than RDX. The reason of the reduction may be due to the catalytic effect of the hydrogen atoms existing in the gaps on the surface of crystal cells.

(3) The conclusion from the ARC experiment is similar to the result obtained from DSC. The apparent activation energy of the mixture $\mathrm{RDX} / \mathrm{MgH}_{2}$ is also lower than that of RDX. The most probable mechanism function changed too. Therefore, it is necessary to ensure the safety of the mixture $\mathrm{RDX} / \mathrm{MgH}_{2}$ before applying it to large-scale experiment.

\section{Acknowledgments}

Professor Zou would like to thank the financial support from Research Funds for the Doctoral Program of Higher Education of China (no. 20100073120007) and from Shanghai Education Commission (no. 12ZZ017). This work is partly supported by projects from the Science and Technology Committee of Shanghai under nos. 10JC1407700, 11ZR1417600, and "Pujiang" project under no. 11PJ1406000.

\section{References}

[1] N. E. Matzek and H. C. Roehrs, "Stabilization of light metal hydride," USP 3857922, 1974.

[2] J. P. Flynn, G. A. Lane, and J. J. Plomer, "Nitrocellulose propellant composition containing aluminum hydride," USP 3844856 , 1974.

[3] J. R. Hradel, “Enhanced organic explosives," USP 3012868, 1961.

[4] A. A. Selezenev, V. N. Lashkov, and V. N. Lobanov, "Effect of $\mathrm{Al} / \mathrm{AlH}_{3}$ and $\mathrm{Mg} / \mathrm{MgH}_{2}$ components on detonation parameters of mixed explosives," in Proceedings of the 12th Detonation Symposium, San Diego, Calif, USA, 2002.

[5] J. R. Ward, " $\mathrm{MgH}_{2}$ and $\mathrm{Sr}\left(\mathrm{NO}_{3}\right)_{2}$ pyrotechnic composition," USP 4302259, 1981.

[6] J. X. Zou, X. Q. Zeng, Y. J. Ying, and W. J. Ding, "Preparation and hydrogen sorption properties of a nano-structured $\mathrm{Mg}$ based Mg-La-O composite," International Journal of Hydrogen Energy, vol. 37, pp. 13067-13073, 2012. 
[7] S. Phetsinorath, J. X. Zou, X. Q. Zeng, H. Q. Sun, and W. J. Ding, "Preparation and hydrogen storage properties of ultrafine pure Mg and Mg-Ti particles," Transactions of Nonferrous Metals Society of China, vol. 22, no. 8, pp. 1849-1854, 2012.

[8] D. I. Townsend and J. C. Tou, "Thermal hazard evaluation by an accelerating rate calorimeter," Thermochimica Acta, vol. 37, no. 1, pp. 1-30, 1980.

[9] J. Huot, G. Liang, S. Boily, A. Van Neste, and R. Schulz, "Structural study and hydrogen sorption kinetics of ball-milled magnesium hydride," Journal of Alloys and Compounds, vol. 293, pp. 495-500, 1999.

[10] L. L. Liu, F. S. Li, C. L. Zhi, H. C. Song, and P. Li, "Effect of magnesium based hydrogen storage materials on the properties of composite solid propellant," Chinese Journal of Energetic Materials, vol. 17, no. 5, pp. 501-504, 2009.

[11] Z. R. Liu, Y. Liu, X. P. Fan, F. Q. Zhao, and C. M. Yin, “Thermal decomposition of $\mathrm{rdx}$ and $\mathrm{hmx}$ part i: characteristic values of thermal analysis," Chinese Journal of Explosives and Propellants, vol. 27, no. 2, pp. 63-72, 2004.

[12] T. B. Brill and P. J. Brush, "Condensed phase chemistry of explosives and propellants at high temperature: HMX, RDX and BAMO," Philosophical Transactions of the Royal Society, vol. 339, pp. 377-385, 1992.

[13] S. F. Palopoli and T. B. Brill, "Thermal decomposition of energetic materials 52 . On the foam zone and surface chemistry of rapidly decomposing HMX," Combustion and Flame, vol. 87, no. 1, pp. 45-60, 1991.

[14] S. Bouaricha, J. Huot, D. Guay, and R. Schulz, "Reactivity during cycling of nanocrystalline Mg-based hydrogen storage compounds," International Journal of Hydrogen Energy, vol. 27, no. 9, pp. 909-913, 2002.

[15] H. E. Kissinger, "Reaction kinetics in differential thermal analysis," Analytical Chemistry, vol. 29, no. 11, pp. 1702-1706, 1957.

[16] T. Ozawa, "A new method of analyzing thermogravimetric data," Bulletin of the Chemical Society of Japan, vol. 38, no. 11, pp. 1881-1886, 1965.

[17] X. M. Qian, L. Liu, and C. G. Feng, "Calculating apparent activation energy of adiabatic decomposition process using pressure data," Acta Physico, vol. 21, no. 2, pp. 134-138, 2005. 

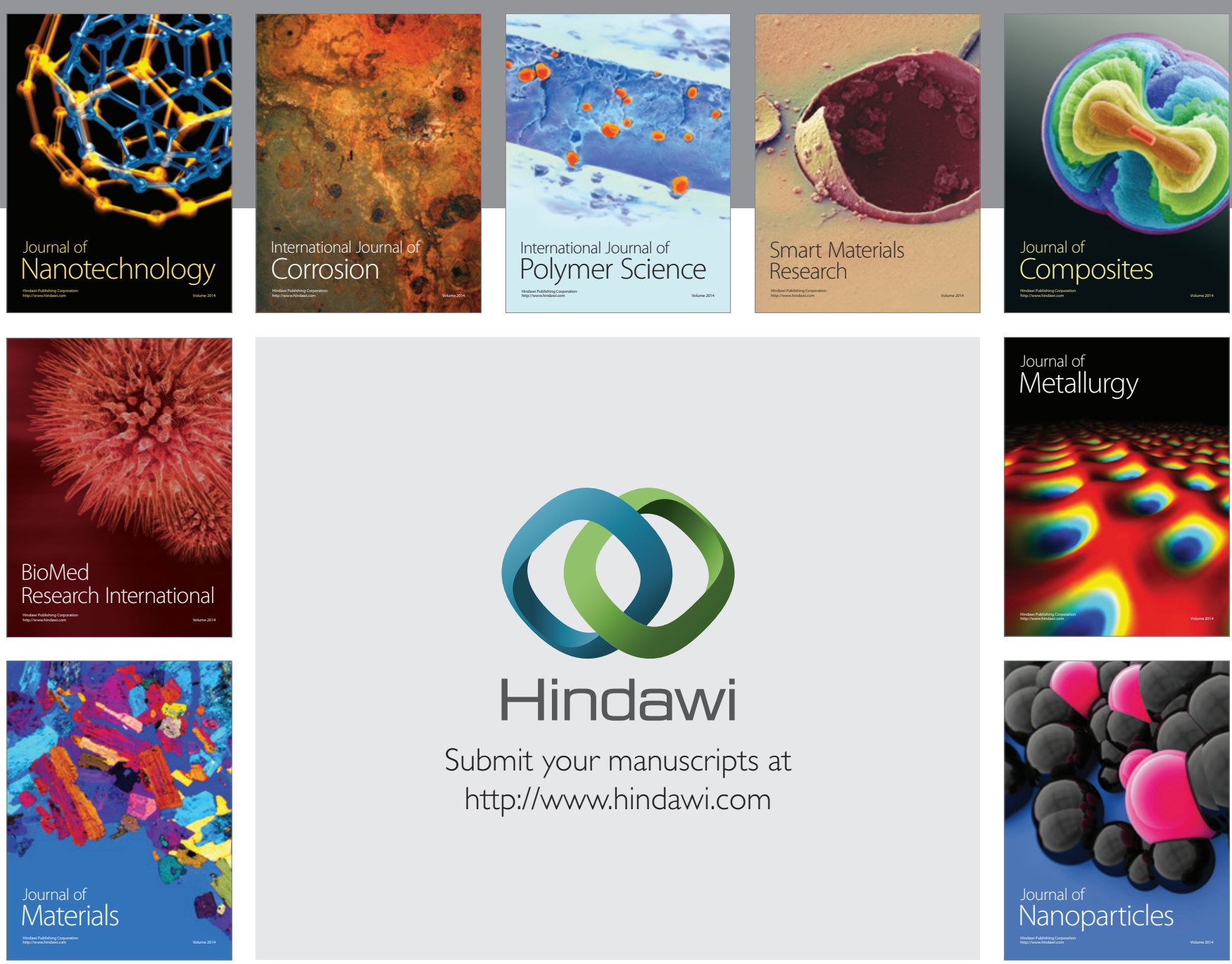

Submit your manuscripts at http://www.hindawi.com
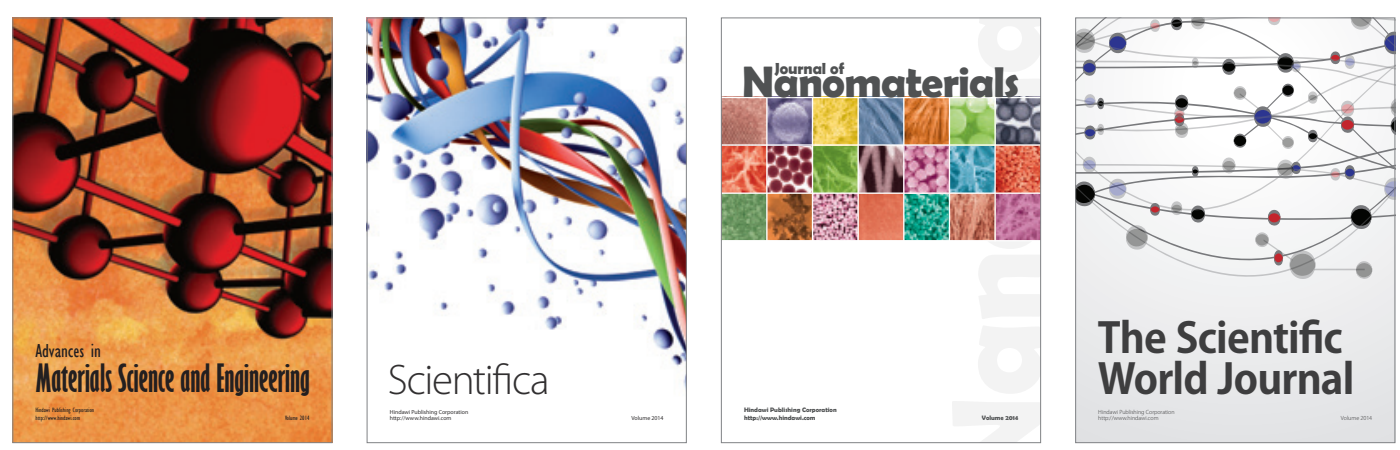

\section{The Scientific World Journal}
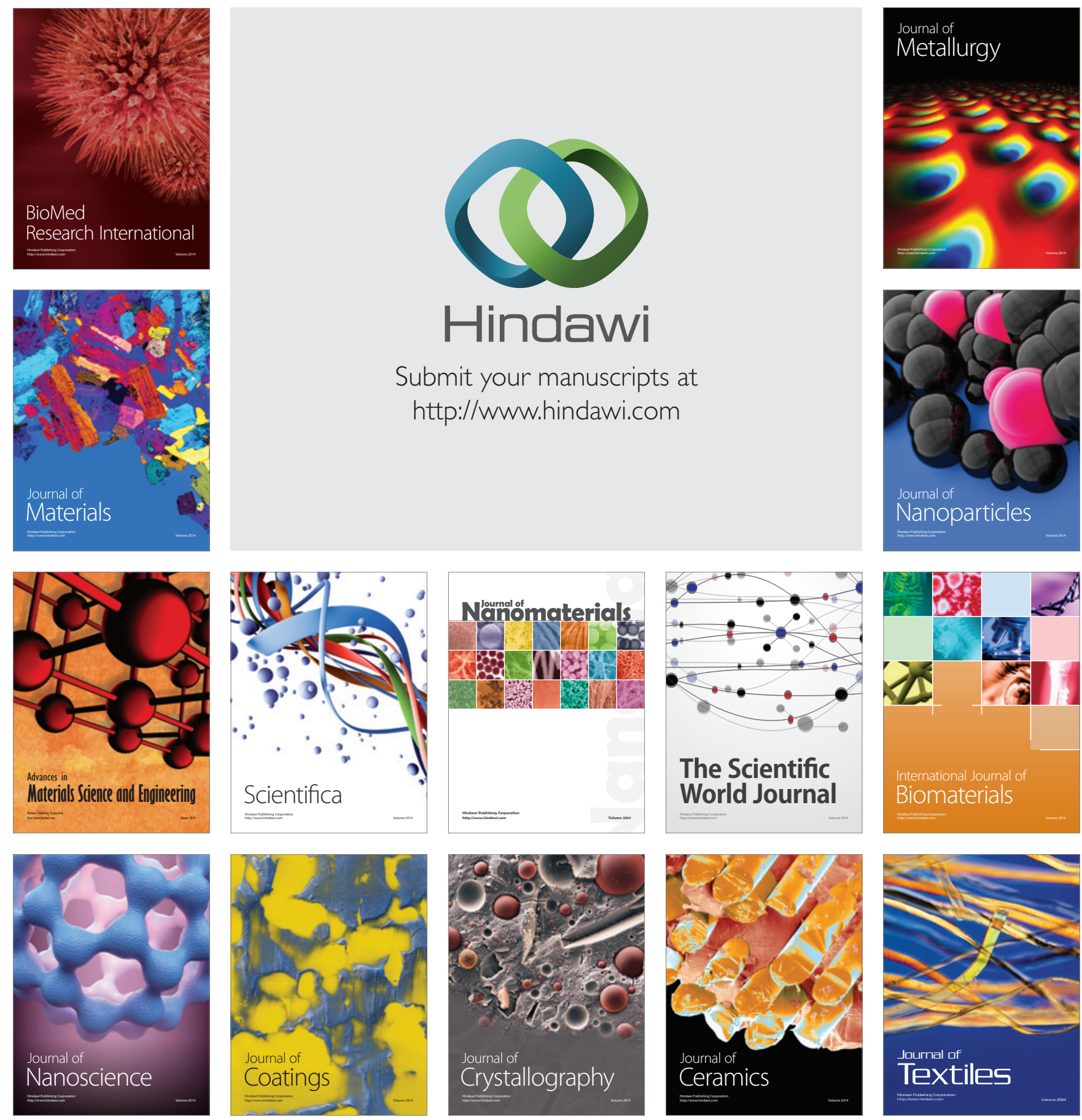